\title{
FROM LANGUAGE GAMES TO SOCIAL SOFTWARE
}

ROHIT PARIKH

CUNY

\author{
"But is this counting only a use then? \\ Isn't there also some truth corresponding to this sequence?" \\ The truth is that counting has proved to pay. \\ Ludwig Wittgenstein
}

\begin{abstract}
It is well known that Ludwig Wittgenstein was not a fan of formalization. It was likely, in his view, that formal results might engender the illusion that some philosophical progress had been made, when in fact no such progress was possible. Nonetheless, in the process of attacking the theory of language formulated in the Tractatus, in the first 45 sections of the Philosophical Investigations, Wittgenstein does put down a road map which would allow us to construct a (partial) theory of meaning. Indeed, once one asks what that theory of meaning might be, the answer is obvious and fits remarkably well with Wittgenstein's remarks.

One could say, roughly speaking, that the Tractatus described one language whose role was to describe the world, and which had therefore to be outside the world. The Philosophical Investigations, PI, by contrast sees language as being in the world and as consisting of a large variety of language games, each of which plays some role in our lives. Our purpose in this paper is to point to at least some similarity among the language games of $P I$ and to propose an account of the role of language which is larger than that contemplated in the Tractatus.
\end{abstract}

\section{INTRODUCTION}

Fairly early in the Philosophical Investigations (PI), Wittgenstein says, (§2) "It is interesting to compare the multiplicity of the tools in language ... with what logicians have said about the structure of language."

"But," one might say, "aren't they all tools ?" And note that the tools in a toolbox ( $\$ 11)$ have little in common with the various items, lipstick, mirror, etc, to be found in a woman's purse. It is unlikely (albeit possible) 
that lipstick will be found in an ordinary toolbox, or that a spirit level will be found in a woman's purse. Thus it may well be that the tools in a toolbox have more in common with each other than Wittgenstein allows, and noticing this fact may allow us to build a partial theory of language. Partial, to be sure, but covering a much larger area than that considered by the author of the Tractatus.

The theory I shall propose will allow us not only to think about the 'meaning', or 'use' of words like "beam", "slab" but also of words like "this", "that", "five" and "red". In particular we will not understand "red" as a unary predicate.

Wittgenstein himself gives us a hint in $§ 7$. "I shall call the whole, consisting of a language and the actions into which it is woven, the "language game'." It is this weaving which much contemporary philosophy of language (albeit not pragmatics) has ignored. ${ }^{1}$

The first suggestion I now make says that a communication situation consists of a parametrized family of procedures and that the way in which a word is used decides which particular member of this family is supposed to be performed by the addressee. This is only a first suggestion and we will need to clarify and expand it as we go along.

Thus consider the command, "Bring $x$ to me" where $x$ is the parameter in question. The four actions which the addressee might perform, i.e., the four members of our family, are, bringing a slab; bringing a pillar; bringing a beam; and bringing a block. If pronouncing the word "slab" results in the bringing of a slab, and the builder is happy with this action, then we can say that "slab" means slab in this context. ${ }^{2}$

Of course there are 24 ways of correlating the four words with the four actions, and if the convention had been that the command "Slab!" resulted in the bringing of a pillar, and the builder was happy with this, then

\footnotetext{
${ }^{1}$ A little boy who had learned a little arithmetic at home, went to his first day of formal schooling and was asked by his mother how his day went. "Everything was fine but the teacher doesn't know anything!", exclaimed the boy. "Why so?" asked the mother. "Well, she actually asked me what two plus three was. Of course I said, five, but shouldn't she have known herself?" said the boy. The boy was used to the game in which $A$ asks $B$ a question to which $A$ does not know the answer. He was not used to the game where $A$, who already knows, asks $B$ a question to see if $B$ knows the answer. Cf. the last two paragraphs of $\S 6$ (in $P I$ ).

${ }^{2}$ It is crucial that the builder be happy with the assistant's action, a matter addressed later by both Grice and Lewis [3, 5].
} 
we would say that the word 'slab' meant a pillar at least in that variant game. ${ }^{3}$

Note now that the same four words (with the normal usage) could be used in a different language game. Imagine that there is a large wooden box at some distance from the builder, and a lot of stones of various shapes lying at the builder's feet. Now in this new game, when the builder says "Slab!", the assistant takes a slab from near the builder's feet and puts it into the wooden box.

Let us call our original language game $G$, and the new game $G^{\prime}$. Does the word "slab" have the same meaning in both games? "Of course", one might say, "for it means a slab in both games." Or one could say, "Of course not, for the assistant does different things in the two games." In game $G$, the word "slab" causes a slab to be brought to the builder whereas in $G^{\prime}$, the same word causes the slab to be taken away from the builder. But in both games, it is the slab which is moved. I want to say, as I suspect Wittgenstein would say, "It is as you please." After all, there is nothing sacred about the word "same".

But clearly the two games cannot be played together because there would be confusion.

However, we can invent a third, larger game, $G+G^{\prime}$ in which the builder utters sentences of the form, " $x, X$ " where $x$ is one of the four words, "slab, beam, pillar, block", and $X$ is one of the two words "here", "there". And now "slab here" will result in a slab being brought to the builder, and "pillar there" will result in a pillar being put into the wooden box.

And now we see the 'difference' between the command "Slab!" in game $G$, and the command "slab, here" in game $G+G$ '. Both these commands result in a slab being brought to the builder. But nonetheless, there is a difference. Clearly the discussion in $§ 19-20$ fits with our analysis. It is not necessary to say more than "Slab!" if one is playing either one of the two games $G, G^{\prime}$. But in the bigger game $G+G^{\prime}$, the words "here" and "there" are necessary and make a crucial difference to whether the object in question is to be brought or taken away. Ordinary language of course is a gigantic game, and it is hard for us to think that "Slab!" is not just an abbreviation for "Bring me a slab!"

But there is no point in saying that "Bring me a slab!" is complete either, for suppose that the builder has two assistants Beth and Carl. If the

\footnotetext{
${ }^{3}$ See, for instance [5] on the importance of speaker and listener agreeing on an interpretation.
} 
builder says, "Bring me a slab", Beth might well respond, "Do you want me or Carl to bring the slab?" The context is always crucial.

But roughly speaking, the same procedure as a member of a larger family of procedures requires more parameters than it does as a member of a smaller family. If the builder and assistant are playing a game in which it is always the case that the assistant brings something to the builder, then it is fine to use the shorter expression, and just say "Slab!" rather than the longer, "Slab, here!".

We have already seen how words like "here" and "there" are used. But now suppose that in a game still larger than $G+G^{\prime}$, say $G^{\prime}$ ", the builder also uses the word "box" to indicate the location to which an object should be taken. Now "slab, there" and "slab, box" will result in the same action. Does that mean that "there" means "box"?

Well, if this is the only game played, then the answer could be "yes". But let us suppose that in the game $G^{\prime \prime}$, the builder has been standing near a chair. Then "slab, here" results in a slab being brought near the chair and "slab, there", like "slab, box" results in the slab being taken to the box. Suppose now, however, that the builder moves so that he is standing near the box. In that case, "slab, box" will still result in the slab being put in the box, but "slab, there" will now result in the slab being put near the chair. Thus the application of "here" and "there" is sensitive to the builder's position whereas that of "box" is not. It would no longer work to say, "there" means "box". Again, if there were several boxes, then "slab, box" may no longer be sufficiently clear.

Let us now consider a word like "five". Suppose, for simplicity that five is the highest number used in the game. ${ }^{4}$ The five procedures which the grocer is to choose among are, put one red apple in the bag; put two red apples in the bag; put three red apples in the bag; put four red apples in the bag and put five red apples in the bag. Now the order "five red apples", chooses the last of the five procedures to be performed by the grocer, whereas "two red apples" would choose the second one. Again there is nothing sacred about the fact that the word "five" results in choosing the last of the five procedures. There are 120 correlations between the five words, "one, two,..., five" and the five procedures. Any of these correlations could be used by the community. But for the customer to be happy with the grocer's actions, it is important that they use the same correlation.

In the example which Wittgenstein uses in $\S 1$, the grocer counts out the five apples one by one. Would it make a difference if the grocer was

\footnotetext{
${ }^{4}$ This restriction is not necessary and is only being made for convenience.
} 
able to take in five apples at a glance, and pick them up as a single group $?^{5}$ Again, it is as we please. The difference between two ways of picking out five apples might be germane, or it might not. But it is hardly likely that one might complain to the grocer, "I wanted you to count out the apples!" But sometimes the process itself does matter. If the first prize in some competition is awarded to the best player without a single match being played, then we will not be happy, even though we might admit that he would have won anyway.

In the game just described, it is always apples which are ordered, and always red. So the single word "five" would have sufficed. But if apples of different colors, and fruits other than apples might also be ordered on some occasion, then the words "red" and "apple" are not superfluous.

We have now given the 'semantics' for various words of rather different kinds, and which is no longer confined to the sort of things, i.e., objects, which St. Augustine was speaking about. In the case of words like "slab" or "beam" which do fit Augustine's theory better, the missing part in the procedure could indeed be filled by pointing to the object in question. If the assistant were to say, "And what do you want me to bring when you say 'Slab!'?" the answer could be given by pointing to the slab. ${ }^{6}$ In the case of the number five, pointing to an object, say some group of five objects would likely misfire, (as Wittgenstein notices) although it is not hard to imagine that in some possible world, there might be five pebbles kept in a sealed box in Paris whose function was to be consulted in case there was ever any doubt as to which number five was (or more precisely, how the word "five" was to be used).

Anyhow, each semantics sits within the context of a language game, and the larger the game, the longer the command needs to be which spells out a particular procedure from the multitude.

"But how does the grocer, or the assistant know which game is being played?" Or, in our terms, which is the family of possible actions from which one is to be chosen? One could say, "Explanations come to an end somewhere." But in fact more can be said on this.

It is by living in society that we learn, within a given context, which game is being played, and what the various alternatives are. It is presumed,

\footnotetext{
${ }^{5}$ This might well be possible if the apples were small.

${ }^{6}$ Although here too, confusion could arise if the assistant thought the word to mean "This particular slab", rather than "any object which looks like this." If the assistant thought that the word meant this particular slab, then he could not fulfill the order "Slab!" a second time.
} 
when you are taking part in a language game, that you already know most of the game, and only some of the parameters are missing. These missing parameters can then be supplied by one of the speakers, but there is no way to explain the entire game in words. At some point, training has to precede explanation, and it is by being members of the same species that we are trainable in particular ways. ${ }^{7}$

The case of Alex, the Pepperberg parrot, is instructive. Suppose a parrot is repeatedly shown a spoon, and each time, someone says the word "spoon", then an association between the word and the object will be established in the parrot's mind. ${ }^{8}$ But as yet he does not know what to do with this association. In other words, the parrot does not know how this association is woven into the language game he has to play.

In order to teach this crucial aspect to the parrot, Irene Pepperberg [11] employed the following procedure. She would employ a subject other than the parrot, and then, with the parrot watching, show the subject the spoon and say, "What is this?" If the subject said, "spoon", then he would get the spoon. If he said something else, Pepperberg would frown and take the spoon away from the subject. Sometimes the subject and Pepperberg herself would interchange roles. After a while the parrot learned to say, "spoon" if he was shown a spoon accompanied by the question "What is this?"

I would like to say, that although he had already associated the word "spoon" with the object spoon, he did not know at first the family of actions in which the word "spoon" would fit as a parameter. After the work with the other subject had taught the parrot the family of possible actions from which one was to be chosen, he knew what to do when a spoon was shown along with the question "What is this?"

In most of these situations the parrot played subgames of the examination game, where we are tested on our knowledge of something, but we do not actually 'make use of' our knowledge. However, when a bored and tired Alex said, "Wanna go back", he was indeed asking to go back to his

\footnotetext{
${ }^{7}$ A friend of mine, Sally Gross, who had taught her grandson to play chess found that he was not playing as she expected. When she complained, he said, "But I am following the rules!" "But you are supposed to try to win," she responded. "Why?" said he, and she had no answer. Is it one of the rules of chess that one has to try to win, and if so, how is this rule enforced? Surely not merely by losing, because one can try to win and still lose, and less likely but possible, one can win even if not trying to win. So there can be no rule that one must try to win, and yet surely it is part of the spirit of the game - a sort of unwritten rule.

${ }^{8}$ I apologize for the anthropomorphic word 'mind'. Feel free to substitute 'brain'.
} 
cage, and be finished with his "exam." These words, "Wanna go back" were then being used for real. It does seem that parrots do not like exams any more than humans do.

\section{ASSERTIONS}

We have been ignoring the part of language which has played the dominant role in the philosophy of language since Frege (if not earlier). So what about assertions?

Here we will heed a suggestion made by Leonard Savage ([12] p.160), and which is of course important also for Austin [1].

Whatever an assertion may be, it is an act and deciding what to assert is an instance of deciding how to act.

An important category is definitions of the form ' $a$ means $A$ '. Then someone who is already used to $A$ as a parameter in some family of games may then be able also to use $a$ also as a parameter. Thus suppose Sylvia is given the command "Feed the hungry" and asks, "Who is hungry?" On being told, "Jack and Jill are hungry. Bill and Carol are not hungry - they have had their dinner" she will then interpret the command "Feed the hungry," as "Feed Jack and Jill."

In [9] the following model of an agent's belief space is used. The belief space $B$ consists of belief states which cause an agent to act and to make choices. Belief states reveal themselves through these choices, which include choices not only of what to do, but also of what to say and what to assent or disagree with. A belief state may be altered by observation of an event, by hearing a sentence, and by a deduction where an agent makes explicit some fact already implicit in his other beliefs.

As in Savage, [12], choices are affected not only by an agent's belief state, but also by the agent's preferences. An agent who would assent to, "It is raining", and who prefers not to get wet, will then take an umbrella when going out.

Since sentences heard change an agent's belief state, the function of an utterance to one agent $A$ by another agent $B$ will then consist of $B$ wanting to influence $A$ 's belief state in order to affect $A$ 's actions. ${ }^{9}$

\footnotetext{
9 Sometimes more than an assertion might be needed as Al Capone noted: "You can get much further with a kind word and a gun than with a kind word alone."
} 
If we assume the co-operative stance presumed by Grice [3], then the sole purpose of $B$ speaking to $A$ would be to improve $A$ 's decision making abilities. Conventionally, we would regard being truthful to $A$ as $B$ 's way of fulfilling this obligation. However, as Grice points out, being truthful to $A$ might not be sufficient.

Suppose for instance that $A$ says, "My car is out of gas", and $B$ responds, "There is a gas station around the corner," then $B$ has implicated, but not said, that as far as $B$ knows, the gas station is open. Thus $A$ is entitled to conclude more than $B$ has actually said, assuming that $A$ and $B$ are involved in a co-operative situation. Thus if $B$ were to say, "There is a gas station around the corner," knowing full well that it wasn't open, he would be truthful, but he would not be playing the game properly.

Now in the gas station example, at least the semantics of "There is a gas station around the corner," and "There is a gas station around the corner and it is open," are clear enough.

However, in [7] an example is given of a sentence which is indeed helpful but where there is no agreed upon semantics. In this example, Ann and Bob are both professors at a small college, Ann has gone to school but forgotten her topology book which she needs for class. She says to Bob:

Bob, can you bring my topology book when you come in?

Bob: What does it look like?

Ann: It is blue.

Bob: $O K$.

However, Bob and Ann assign different extensions to the word "blue". 10

In particular, among Ann's 1,000 books, there are 250 to which Ann would assign the color blue, and of these 250 , Bob would also assign the color blue to 225. However, Bob also considers blue another 75 books which Ann would not call blue. On hearing Ann say, "It is blue," Bob will look among the 300 books that he considers blue, following up, if needed, with a search through other books that are, from his point of view, arguably blue.

Thus there is no proposition which Ann is conveying to Bob when she says that her book is blue. The sentence uttered by Ann is interpreted differently by Ann and Bob. Nonetheless, given a book that Ann calls blue, there is a fairly high chance that Bob would also call it blue.

\footnotetext{
${ }^{10}$ This is not a qualia issue, but simply a function of the fact that there are of necessity slight or even substantial differences in individual usages of color words.
} 
It is shown in [7] that Ann's statement "It is blue" reduces Bob's time in looking for the topology book by (at least ${ }^{11}$ ) 60\%. Thus Ann has helped Bob (and herself) even though strictly speaking, no 'information' has been received by Bob.

Despite valiant attempts, there has been no fully successful theory of vague predicates, and therefore of the meaning of the sentence "It is blue." But if we ask, "What use is an utterance of "It is blue?", then the answer is ready at hand.

\section{DECEPTION}

The assumption made by Grice is to the effect that when two people are communicating, there is co-operation between them, and the presumption of the co-operation allows for more to be conveyed than is literally said. However, the presumption of co-operation cannot always be taken for granted. There are occasions when $A$ 's interests and $B$ 's interests do not coincide perfectly, or when $B$ has more at stake than simply benefitting $A$.

A mathematical analysis of such a phenomenon (in the context of conventional utility theory) was carried out by Crawford and Sobel [2] in 1982. ${ }^{12}$ They show that in their framework, the amount of information which $B$ can transmit to $A$ is limited by the extent to which $A$ and $B$ have common interests. In particular, if the interests are completely opposed, as happens in a zero sum game, no information can reliably be conveyed. Clearly $B$, in attempting to influence $A$ 's actions, is attempting to benefit himself, and in a zero sum game, any benefit to $B$ is a loss to $A$. $A$, knowing this, will take all of $B$ 's statements with a grain of salt. Moreover, $B$ cannot take for granted that $A$ will take all of $B$ 's statements to be lies, since $A$ knows perfectly well that if $B$ could rely on $A$ taking $B$ 's statements to be lies, $B$ could take advantage of this knowledge.

In brief, there is no Nash equilibrium of information transmission in a zero sum game.

However, it may well be that the interests of the two parties are sufficiently aligned that some communication is possible. For instance, during the cold war, the US and the USSR were opponents. But avoiding all out war was something that both sides wanted. Thus their interests were par-

\footnotetext{
${ }^{11}$ Had Bob had the same denotation for 'blue' as Ann did, the time would have been reduced by $75 \%$.

${ }^{12}$ See also [14].
} 
tially aligned. Having a hot line, for instance, was a way of acknowledging the commonality of interests, and the possibility of partial communication.

Crawford and Sobel show that in the situation where the interests of the two sides are partially aligned, some limited communication is possible. While neither party can wholly trust the other, partially believing the other party can be to one's advantage.

\section{CONCLUSION}

We have suggested in this paper that the usage of words can often be understood in terms of a particular word picking out a particular action (or perhaps procedure) from a family of such possible actions. And there is also a presumption that the particular action which is picked out is the one which is 'wanted' in some sense. if we accept Wittgenstein's tacit suggestion that language games are played because there is some benefit to society, then we can see him as having anticipated, at least in spirit, some of the more recent developments in game theory, and especially in game theoretic pragmatics, see, for instance, [6].

Moreover, the question, "What use is this assertion?" may allow us to understand communication better than the question, "What does this sentence mean?"

\section{ACKNOWLEDGEMENT}

This work was partially supported by a grant from the PSC-CUNY faculty research assistance program.

\section{REFERENCES}

[1] J.L. Austin. How To Do Things With Words, Harvard University Press, Cambridge, second edition, 1975. ed. J. O. Urmson and Marina Sbisa.

[2] V. Crawford, and J. Sobel (1982) "Strategic Information Transmission", Econometrica 50, pp.1431-1451.

[3] Paul Grice, Studies in the Way of Words, Harvard U. Press, 1989.

[4] Jeffrey Helzner, "Expected content", The Review of Symbolic Logic, 1:4, December 2008, pp.424-432

[5] David Lewis, Convention: a Philosophical Study, Havard U. Press, 1969. 
[6] Prashant Parikh. "Communication and Strategic Inference", Linguistics and Philosophy, 14, pp.473-514, 1991.

[7] R. Parikh, "Vagueness and Utility: the Semantics of Common Nouns", Linguistics and Philosophy, 17 (1994), pp.521-535.

[8] R. Parikh, "Social Software”, Synthese, 132, Sep 2002, pp.187-211.

[9] R. Parikh, "Sentences, Belief and Logical Omniscience, or What does Deduction Tell Us?" Review of Symbolic Logic 1:4 (2008), pp.459-476.

[10] R. Parikh, and R. Ramanujam, "A Knowledge based Semantics of Messages", in J. Logic, Language and Information, 12, (2003), pp.453-467.

[11] Irene Pepperberg, "Talking with Alex: Logic and Speech in Parrots; Exploring Intelligence," Scientific American Mind, August 2004.

[12] L. J. Savage, The Foundations of Statistics, Wiley 1954.

[13] R. Stalnaker, Context and Content, Oxford University Press, 1999.

[14] R. Stalnaker, "Saying and Meaning, Cheap Talk and Credibility", In Anton Benz, Gerhard Jäger, and Robert van Rooij, editors, Game Theory and Pragmatics, pp.83-100. Palgrave Macmillan, New York, 2006.

[15] Ludwig Wittgenstein, Philosophical Investigations, MacMillan, 1958.

[16] Ludwig Wittgenstein, Remarks on the Foundations of Mathematics, revised edition, MIT press, 1978.

[17] Ludwig Wittgenstein, Tractatus Logico-philosophicus, London, Routledge \& Paul; New York, Humanities Press, 1961. 
